\title{
Initiating Software Process Improvement in Very Small Enterprises
}

\section{Experience with a Light Assessment Tool}

Naji Habra ${ }^{1}$, Simon Alexandre ${ }^{2}$, Jean-Marc Desharnais ${ }^{3}$ Claude Y. Laporte ${ }^{4}$, Alain Renault ${ }^{5}$

\footnotetext{
${ }^{1}$ University of Namur (Belgium), PReCISE Research Center, nha@info.fundp.ac.be
}

${ }^{2}$ CETIC (Centre d'Excellence en Technologies de l'Information et de la Communication) (Belgium), simon.alexandre@cetic.be ${ }^{3}$ Ecole de technologie supérieure (Québec, Canada), jean-marc.desharnais@etsmtl.ca

${ }^{4}$ Ecole de technologie supérieure (Québec, Canada), claude.y.laporte@etsmtl.ca

${ }^{5}$ Centre de Recherche Public Henri Tudor (Luxembourg), alain.renault@tudor.lu 


\section{Initiating Software Process Improvement in Very Small Enterprises Experience with a Light Assessment Tool}

\begin{abstract}
The paper concerns software process improvement in Very Small Enterprises (VSEs). It presents briefly a gradual methodology to initiate software process improvement in VSE through three steps approach and develops the first and most original step. This first step is based on a light evaluation achieved by means of a dedicated Micro-Evaluation approach. It has been experimented during 7 years in 86 organizations from three countries. The experience with that utilization tends to show that such a light approach is practicable and promising, at least for the targeted enterprises.
\end{abstract}

Keywords: Software Process Improvement (SPI); Process Evaluation; $\mathrm{CMMI}^{\mathrm{SM}}$; OWPL; MicroEvaluation; Very Small Enterprises (VSE), Small Settings.

\section{Introduction}

The challenge posed by software process improvement for very small enterprises, or VSEs (with fewer than 25 employees), is markedly different from that for larger enterprises. This is mainly because of differences in their awareness of quality issues and in the resources available to them.

Larger enterprises involved in the development of Information Technology (IT) products and services are more aware of the importance of performance, quality and development time. As a result, they trend to invest time and resources in improving their software product quality and development processes. Some have created their own reference model for that purpose, but most use models such as the Capability Maturity Model Integration $\left(\mathrm{CMMi}^{\mathrm{SM})}\right.$ [1] of the Software Engineering Institute (SEI) or the ISO/IEC-15504 standard of the International Organization for Standardization (ISO), commonly known as SPICE (Software Process Improvement and Capability dEtermination) [2].

One of the major characteristics of VSEs is the lack of resources assigned to the software process in general and to quality improvement tasks in particular. In fact, small software structures have, by definition, small teams, and people are absorbed by pressing matters related to the tight deadlines that are generally attached to production tasks.

Common models like CMMi and ISO 15504 are not readily usable by these organizations. They are much too complicated and too expensive to implement. Moreover, as a consequence of the lack of resources and expertise, the VSE software process usually ranks very low relative to common software process maturity scales like the $\mathrm{CMMi}^{S M}$. In spite of this, a large number of small settings are undoubtedly remarkably successful and show obvious technical competence in their specific technical domain. The global weakness of their software process must therefore be considered closely to get a more refined view.

From this viewpoint, we can claim that it is possible to quickly and substantially improve software process in VSEs by means of a well-disciplined and welltargeted approach that does not necessarily require disproportionate investments. It is on this basis that we present here the OWPL ${ }^{6}$ gradual Software Process Improvement (SPI) approach.

The next section summarizes the particular features of VSEs that have motivated the development of this approach. Section 3 presents the framework used, along with the underlying models. In section 4, the Micro-Evaluation model in particular is presented. Our experience with the Micro-Evaluation model (version 1.0) in 86 small organizations in three countries is detailed in section 5 . Then, some concluding remarks

\footnotetext{
${ }^{6}$ OWPL stands for "Observatoire Wallon des Pratiques Logicielles" the name acronym of the initial project.
} 
drawn from the experience are presented in section 6 . Finally, future works are proposed in section 7.

\section{Software Process in-the-small}

Despite the great diversity in the maturity level of the various software processes implemented in individual companies and in different VSEs, they all have some characteristics in common. These characteristics, which were posed as working hypotheses at the beginning of our work, are largely confirmed by the observations made throughout the experience. (They also appeared to be corroborated by different parallel studies on Small and Medium Enterprises which are discussed mentioned in 3.3 below).

- The software life cycle is often highly simplified. Generally, even some of its main phases (e.g. analysis, implementation, maintenance...) are not completely formalized. Development and testing are usually the two most important phases. Even though testing is usually considered to be the most important phase after the development, it is often shortened to meet deadlines or because of lack of resources.

- The maturity levels of processes within the same organization can be very unequal: very good processes can be combined with very low-level ones. High-quality practices are often legally or contractually imposed customer-supplier relationship practices, which are, most of the time, considered as a burden rather than an asset by the organization itself.

- In general, quality control procedures are too poorly formalized. In view of the lack of control, the motivation to adhere to new procedures can quickly disappear.

- No common features could be observed in most VSEs concerning project management and planning practices. Some have a very good project management process while others do not. But practices can be very uneven within the same organization, depending on the project, client, project manager or development team concerned.

- The resources devoted to training and human resources practices are usually very limited due to severe budget constraints in general. Training activities are often carried out in response to specific technical deficiencies. They are considered to be an "emergency exit" in cases where team members are unable to effectively self-train.

- Small settings are project-oriented: their processes are rarely driven by a long-term strategy. Consequently, learning and knowledge management practices can rarely be observed. This is commonly observed in larger structures as well, of course. However, there is more evidence of it in VSEs.

- Because of its size, a VSE has difficulties to impose a methodological approach -even if it is a very good one- upon a larger business partner.

- Usually, there is no risk management. This is related to the short-term view reported above. In practice, the risk taken can be extremely high, though uncalculated. This explains why some small structures experience the most spectacular success.

- Quality issues are not addressed explicitly with a real involvement of management.

Finally, at the International Organization for Standardization (ISO), it has also been found that international software standards are difficult to apply in VSEs. ISO/IEC JTC1 SC7 established a Working Group, WG24, to address some of these difficulties by developing profiles and by providing guidance for compliance with ISO software engineering standards for VSEs of lower maturity levels [3].

\section{Global View of the Gradual Framework}

\subsection{Origin}

Based on the above observations, the University of Namur (Belgium) initiated, during the years 1998-2000, a Software Process Improvement SPI approach dedicated to VSEs. The approach, called OWPL was developed, continually improved and implemented experimentally by a larger collaborative effort involving CETIC (Wallonia, Belgium), the École de technologie supérieure (ÉTS) (Québec, Canada) and the Centre de Recherche Public Henri Tudor (Luxembourg).

The overall objective of the global approach is twofold: to draw the attention of small structures to SPI matters, and to help them bring their software practices to a more homogenous level in order to begin a continuous improvement process. This objective led us to propose a gradual approach (Figure 1) based on a three-stage software process improvement framework.

\subsection{Gradual Approach Schema}

The gradual approach involves a series of three assessments: Micro-Evaluation, OWPL evaluation and SPICE, CMM or CMMi assessment. 
Figure 1: The OWPL Gradual Approach

In the first stage, Micro-Evaluation is used to collect information about the current software practices in small settings and to sensitize people to the importance of software quality. The information collected is then used as a starting point to determine the scope and target of a more accurate evaluation using the OWPL model, which was developed on the same basis $[4,5,6,7,8,9]$. Larger companies with a medium-to high maturity level can eventually undertake an ISO/IEC 15504, or a CMMI-based appraisal if this appears appropriate.

Each stage of the gradual approach can constitute the reference point for one or more improvement cycles before the next stage is considered. An organization can also iterate with the tool and reference model that fits. This depends on the particular context of the organization (including the score at the current stage, the organizations goals...).

\subsection{Similar Initiatives}

Several similar initiatives related to SME and VSE can be found in the literature [10-20]. Following the increasing use and diffusion of the SW-CMM in the 90's and the diffusion by SEI of its benefits, several practitioners underlined the need of adapting these initiatives to VSE's (e.g., Error! Reference source not found.,Error! Reference source not found.,[14] and [18]). Several initiatives have been developed in parallel with OWPL (e.g., [16] and [17]). Most recent approaches have been published like the ADEPT approach integrating -more than OWPL did- the iterative concepts coming from the Agile research field, (e.g., [19]).

Our approach presents some distinctive aspects but also a number of similarities with those initiatives. For example:

- The OWPL model has been influenced by both SPICE and the CMM; the former has more impact the latter. Other tailoring initiatives use different models as a basis (e.g., the TAPISTRY [18] initiative is based on BOOTSTRAP).

- The OWPL approach focuses on the lowest maturity levels (1-3), an organization having reached a adequate level is invited to go ahead with a standard model, e.g. CMMi, SPICE. The main goal is to initiate improvement process. Other approaches focus also lower levels, e.g. [21] focuses explicitly CMM level 2.

- OWPL approach focuses more on education than on documentation and formalization. In some other approaches, e.g. the PROCESSUS [15], standard processes and standard documentation remain central issues.

- A important correlation can be found at the level of the processes considered as the most critical for SME and VSE, the vocabulary differs (relatively to the original model/models) but key practices are frequently similar (e.g. practices related to customer requirements and project management).

The remainder of this paper focuses on the MicroEvaluation approach (Section 4) and its deployment in Wallonia, Québec and France (Section 5). Details on the gradual approach framework and on the OWPL evaluation can be found in $[4,5,6,7,8,9]$

\section{The Micro-Evaluation Model and Tool}

\subsection{Elaboration of the Micro-Evaluation model \& tool}

The project was initiated by the University of Namur at 1997 as a part of Walloon initiative to sensitize regional IT enterprises (mainly VSEs) to software quality issues. Practically, we started with an awareness action where the regional SMEs were invited to a series of conferences-debates on software quality. The expressed demands have shown that a great majority of the concerned businesses have small software teams and very limited resources; this is corroborated by different studies on regional Small and Medium Enterprises (see e.g. the regional study in [22]) and others regions similar approaches, e.g. $[10,16])$. Meanwhile, the fact 
that those small businesses evolve in a European open market with increasing competition makes the software quality a crucial issue for them all.

The next step was a pilot experimentation on voluntarily candidate organizations. After designing a first experimental version of the Micro-Evaluation tool on the basis of common process models (not reported here see e.g. [5]), we experimented it on a sample of twenty pilot organizations. The sample was composed of VSEs in IT services, together with 2 small IT teams in large businesses and 3 small IT teams in public administrations.

All of the assessed organizations declared to be satisfied with the results and the great majority demanded to continue the SPI with our team, either through a second Micro-Evaluation, through personal guidance, through the supply of information on SPI subjects or through an OWPL evaluation. The assessed organizations allowed us to gather a rich knowledge base on software processes in SME's (see Section 2) and provided us with very useful feedback. This feedback allowed us to refine our tool and to propose the first version to other regional SME. Subsequently, this version was proposed and used, with the collaboration of partners, to other countries.

\subsection{The Goals of Micro-Evaluation}

The Micro-Evaluation approach is designed to provide an initial assessment of software practices at the lowest possible cost. The rationale is twofold: to make the VSE aware of its strengths and weaknesses and the potential improvements it can expect on the one hand, and to determine the priorities of those improvements on the other.

The strategic objective at the heart of the MicroEvaluation approach was to improve the global maturity level of software practices in VSEs. The first step in achieving this at the company level was to help the software VSE to implement SPI. In that context, four high-level goals had been identified:

- Sensitize the organization to quality issues;

- Conduct a high-level inventory of the organization;

- Prioritize the steps of the improvement process;

- Allow organizations to realize Software Process Assessment with very few resources.

\subsection{The questionnaire and the rating}

The questionnaire is used by an assessor to interview a representative of the organization being evaluated. The assessor must have sufficient expertise in software quality and software process improvement. The interviewee should also have sufficient knowledge of the organization's IT activities.

The interview is more efficient than a self-assessment, as it allows the interviewer to adapt the vocabulary according to the interviewee and prevents questions from being misunderstood. In this way, the interview can be considered as an exchange of information rather than as an audit.

In order to meet the lowest-possible-cost objective, a phone call-based interview has been defined, so that the time investment on the part of the organization is limited to 45 minutes to one hour!

The questionnaire itself contains 18 queries. One of them relates to a brief description of the assessed organization to capture its particular context. Another pertains to the interviewer's remarks concerning the questionnaire by itself. The other 16 queries cover 6 practice areas (called also evaluation axes). These axes are:

1. Quality management,

2. Customer management,

3. Subcontractor management,

4. Development and project management,

5. Product management, and

6. Training and human resources management

Those queries are regrouped such that evaluating each practice area involves between 1 and 5 queries.

Each query starts by an open question which is associated with one or more sub-questions, allowing the interviewer to adjust and refine the answers as necessary in order to bring the interviewee to give the precise information needed to fit the scale. There are two types of queries. The first type addresses general practices related to the organization. These are rated on a linear scale according to the maturity of the practice assessed. Here is an example of a query of this type:

Question: What relations, what contacts do you undertake with your subcontractor(s) during their part to the project?

Sub-question: Does the supplier regularly take part to project activities?

\begin{tabular}{|l|l|}
\hline Proposition & Answer \\
\hline Not Applicable & \\
\hline Only if necessary & \\
\hline On a regular basis, on fixed milestones & \\
\hline As often as possible & \\
\hline $\begin{array}{l}\text { Continuously, the supplier participates to } \\
\text { the project }\end{array}$ & \\
\hline
\end{tabular}

Table 1: Example of query (type 1)

The second type of queries addresses software practices, which are rated on a two-scale table according to the maturity of the practice, on the one 
hand, and the effectiveness of its implementation in the organization, on the other hand. Here is an example of the second type of queries

Question: How do you monitor your subcontractor' activities?

Sub-question: Do you keep touch with your subcontractors during the projects?

Sub-question: Do you hold regular meetings with your subcontractor?

\begin{tabular}{|l|l|c|}
\hline \multicolumn{1}{|c|}{ Proposition } & $\begin{array}{c}\text { some } \\
\text { projects }\end{array}$ & $\begin{array}{c}\text { all } \\
\text { projects }\end{array}$ \\
\hline Occasional meetings, on demand & & \\
\hline Regular meetings & & \\
\hline \multicolumn{2}{|c|}{ Table 2: Example of query (type 2) }
\end{tabular}

Scales for both types of queries use values, ranging from 0 to 4, that correspond roughly to the ISO-15504 NPLF (Not-Partially-Largely-Fully). The role of the assessor is to consider to what extend the information given by the interviewee corresponds to one of those values. The score of each practice area is obtained by taking the mean of the corresponding queries' scores.

Evaluating practice areas according to a reference grid makes it possible to draw up a maturity profile for each practice and to eventually measure the progress made between two evaluations of the same practice (Figure 2 shows an example).

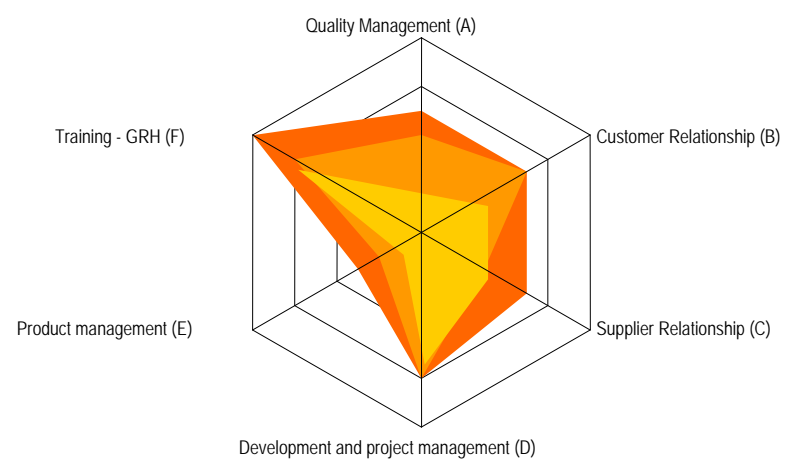

Figure 2: Evolution according to a summary profile

In addition, the interviewee is also asked whether or not existing practices are efficient and to provide expected results. This information, though with no impact on the profile, is very helpful in drawing conclusions in the evaluation report in the appropriate context.

Conclusions include general recommendations and specific improvement actions. Those are of course discussed and prioritized with respect to the organization's context and goal. Subsequent MicroEvaluations can then be proposed to measure the improvement. An organization with an adequate level (usually with no axis rated below three) is proposed to go beyond the Micro-Evaluation level and to use the more elaborated OWPL model to govern its subsequent improvement cycles. In such cases, the conclusions of the Micro-Evaluation will help determining priorities for subsequent actions.

\subsection{The Micro-Evaluation report}

Micro-Evaluation results are presented in a report of $+/$ 20 pages written by the evaluator(s) on basis of a predefined template. The report starts with an introductory section in which the VSE environment and the circumstances that led to the Micro-Evaluation are described. It then briefly presents the approach and the results of the evaluation, summarizing them according to the six evaluation axes. Subsequently, these results are analyzed according to the context of the organization concerned (age, history, declared goals, difficulties, results obtained, etc.). A list of the main strengths and weaknesses of the practices according to SPI principles is also drawn up. Finally, recommendations are proposed to help the assessed unit to improve. The report is confidential and sent to the individual who participated in the evaluation.

Before going on the description of the field experience, it is worth mentioning some inherent limitations of the approach. The reliability of conclusions obtained on basis of one interview of 45 minutes depends of course on the interviewee's perception. Those allow only building up practicable hypotheses to go through first improvement cycles. Recall that the Micro-Evaluation main goal is to give a first insight but no in-depth analysis. In our methodology, such analysis is achieved through the next step, the OWPL evaluation that requires more than one person to be interviewed for each process.

In addition, as a number of Micro-Evaluations were performed on a single project or team, that the accuracy of the analysis for the other teams or projects was not evaluated.

\section{The Experience}

This section develops the deployment of the MicroEvaluation tool described above and summarizes the important facts about the results.

\subsection{The context}

The Micro-Evaluation has been used since 1998 in Wallonia, Quebec and France in more than 80 companies such as small IT companies, small IT services in other businesses and public administrations. 


\section{The Micro-Evaluation in Wallonia (1998-2005)}

Micro-Evaluation was first tested in 1998 and 1999 on a sample of twenty organizations made up of small IT companies, IT departments in public administrations or private companies. During a second round, from 2000 to 2005, new companies together with seven of the companies evaluated during the first round were (re)evaluated with the Micro-Evaluation tool. In total, 31 different organizations have been evaluated with the Micro-Evaluation tool in Wallonia (seven of them have been evaluated twice).

The Micro-Evaluation in Quebec (2004-2005)

In the summer and fall of 2004 and 2005, 21 MicroEvaluations were performed in Montréal. A second round of Micro-Evaluations was then performed in 2005 on 25 new companies. In total, 46 different organizations have been evaluated with the MicroEvaluation tool in Québec.

The Micro-Evaluation in France (2005)

In the summer of 2005, 9 evaluations were performed.

In summary the reported experience concern 93 evaluations of 86 different organizations in 3 countries. In fact, 7 organizations have been evaluated twice; the second evaluations results have been used to observe the improvement. In this paper, only results of the first evaluations are taken into account.

\subsection{Results}

The summarization of the results given in this section aims at giving a global observation of SME characteristics (if any) and tries to handle the geographic parameter. A more detailed statistical analysis focusing on other parameters (e.g., project type and size, development process, market etc.), although worthwhile, is difficult to achieve (incomplete data, great dispersion of available values...).

\section{Global view}

Figure 3 gives a global view of the results by detailing, according to the 6 axes, the frequencies of organizations having reached a given level (as a percentage of the all the organizations evaluated).

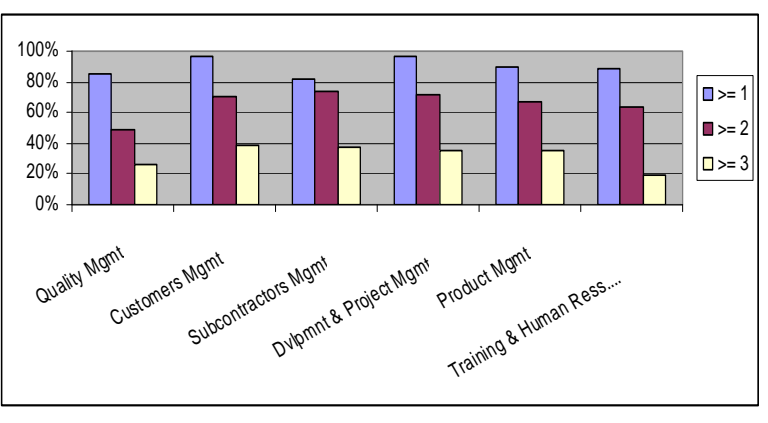

Figure 3: Global view of the results

The figure shows some differences between axes. Though these differences are not significant to draw definitive conclusions, however their observation shows some trends.

Results are presented on basis of "cumulative frequencies", i.e., the number of results greater than or equal to a reference value (we use 1, 2 and 3 ) divided by the total number of results. We avoid the use of statistical "means" because of the scale type. In fact, the scale type is ordinal. It represents just an ordering on the evaluated organizations, but nothing more (there is no "distance" notion). So, two organizations which have been evaluated to $\mathrm{X}$ and $\mathrm{Y}$ for some axis with $\mathrm{X}>\mathrm{Y}$ means that the first one has "more mature practices" for that axis that the other, but nothing more. In particular, the addition $\mathrm{X}+\mathrm{Y}$ or the mean $(\mathrm{X}+\mathrm{Y}) / 2$ have no sense.

\section{Wallonia}

Weaknesses (under 2 points for more than one-third of the organizations) are observed in the majority of topics. But the most critical weaknesses are observed for the development methodologies (in the axis development and project management) scoring under 2 points for more than two-thirds of the organizations.

It is worth noting that the results of Wallonia's companies, as illustrated in table 3 , were obtained in the first round of the evaluation. They are thus the less recent ones (1998-2000), which could explain this generalized weakness. Our subsequent evaluation rounds (not reported in this paper, see [10]) show a real improvement which brings those companies to the level of the results in France and Quebec obtained more recently and reported below. 


\begin{tabular}{|r|c|c|c|c|}
\hline & $>=\mathbf{1}$ & $\mathbf{> = \mathbf { 2 }}$ & $\boldsymbol{> = \mathbf { 3 }}$ & $>\mathbf{4}$ \\
\hline Quality Mgmt & $94 \%$ & $48 \%$ & $29 \%$ & $10 \%$ \\
\hline Customers Mgmt & $97 \%$ & $71 \%$ & $35 \%$ & $3 \%$ \\
\hline Subcontractors Mgmt & $95 \%$ & $74 \%$ & $32 \%$ & $16 \%$ \\
\hline Dvipmnt \& Project Mgmt & $97 \%$ & $61 \%$ & $16 \%$ & $0 \%$ \\
\hline Product Mgmt & $77 \%$ & $52 \%$ & $16 \%$ & $3 \%$ \\
\hline Training \& Human Ress. Mgmt & $90 \%$ & $77 \%$ & $26 \%$ & $19 \%$ \\
\hline
\end{tabular}

Table 3: Summary of Wallonia Results

Quebec

The Quebec results, as illustrated in table 4, show that small organizations performed well (with a score $>2$ for more than two-thirds of the organizations) on a majority of topics. Particularly good results are observed in subcontractor tracking, requirement formalization (customer management axis), versioning activities (product management axis) and verification (development and project management axis). A number of weaknesses (under 2 for more than one-third of the organizations) can also be noted on commitment to quality with $59 \%$ of organizations under 2 and the origin of quality with $37 \%$ under 2 (both in the quality management axis), product structure (in product management axis) with $41 \%$ under 2 , and human resources management with $39 \%$ under 2 . It is interesting to note that the scores obtained for Quebec do not fluctuate significantly, which corroborates the finding of maturity level evenness within the organizations.

\begin{tabular}{|r|c|c|c|c|}
\hline & >= 1 & >= 2 & >= 3 & >= 4 \\
\hline Quality Mgmt & $78 \%$ & $54 \%$ & $26 \%$ & $11 \%$ \\
\hline Customers Mgmt & $98 \%$ & $70 \%$ & $37 \%$ & $13 \%$ \\
\hline Subcontractors Mgmt & $88 \%$ & $88 \%$ & $59 \%$ & $29 \%$ \\
\hline Dvlpmnt \& Project Mgmt & $96 \%$ & $80 \%$ & $50 \%$ & $9 \%$ \\
\hline Product Mgmt & $96 \%$ & $74 \%$ & $43 \%$ & $37 \%$ \\
\hline Training \& Human Ress. Mgmt & $89 \%$ & $61 \%$ & $20 \%$ & $20 \%$ \\
\hline
\end{tabular}

Table 4: Summary of Québec Results

France

The results for France, as illustrated in table 5, show that the targeted organizations performed quite well. Particularly good results (with a score $>2$ for more than two-thirds of the organizations) are observed on project planning (project management axis), requirement formalization, change management and customer integration (customer management axis), product structure and versioning activities (product management axis). The assessed weaknesses pertain to the activities related to the quality management axis: commitment to quality (66\% of organizations with score under 2) and problem management (78\% of organizations with score under 2). It is to be noted that half these organizations had no supplier, biasing the "Subcontractor selection" axis.

\begin{tabular}{|r|c|c|c|c|}
\hline & $>\mathbf{1}$ & $>\mathbf{= 2}$ & $>=\mathbf{3}$ & $>\mathbf{= 4}$ \\
\hline Quality Mgmt & $89 \%$ & $22 \%$ & $11 \%$ & $0 \%$ \\
\hline Customers Mgmt & $89 \%$ & $78 \%$ & $56 \%$ & $22 \%$ \\
\hline Subcontractors Mgmt & $44 \%$ & $44 \%$ & $11 \%$ & $0 \%$ \\
\hline Dvlpmnt \& Project Mgmt & $100 \%$ & $67 \%$ & $22 \%$ & $0 \%$ \\
\hline Product Mgmt & $100 \%$ & $89 \%$ & $56 \%$ & $22 \%$ \\
\hline Training \& Human Ress. Mgmt & $78 \%$ & $33 \%$ & $0 \%$ & $0 \%$ \\
\hline
\end{tabular}

Table 5: Summary of France Results

\subsection{Analysis of results}

In this section, the assessment scores from the three sets of data (France, Quebec and Wallonia) are discussed. Even though the sample does not claim to be representative of the world's small and very small organizations, the features that characterize small and very small settings are similar in the sample. The sample has the advantage to be rather large for this kind of study and covering a diversity of organizations.

A first observation one can make is that the results show a good distribution around the value 2 with no concentration around extreme values. This is one argument in favor of the appropriateness of the assessment tool scale to the targeted organizations (which are supposed to have low maturity level according to standard scales like CMMi) on the one hand, and to the intended use (encouraging those organizations to accomplish first small improvements before entering in the other standard scales) on the other hand.

\section{Quality Management}

This is the weakest key area, over $51 \%$ of the scores being under 2 . With regard to the origin of quality, $42 \%$ have a score under 2 .

\section{Customer Management}

This is one of the highest key areas, where $75 \%$ of the organizations scored 2 or more. Requirements formalization achieved the highest score, only $17 \%$ having a score under 2 and $44 \%$ even scoring 4 .

\section{Subcontractor Management}

Many enterprises do not use suppliers. For those who do, it was found that $86 \%$ scored 2 or more. 
Development and Project Management

Over $73 \%$ scored 2 or more. It is the verification practices (i.e. tests) that scored quite high, 90\% scoring 2 or more. Development methodology scored lowest, at $56 \%$.

\section{Product Management}

Versioning and product structure scored an average of $66 \%$. Versioning is the strongest practice at $73 \%$, and $44 \%$ scored 4.

\section{Training and Human Resources Management Over $64 \%$ scored 2 or more.}

No significant differences can be observed between the various regions or between the key axes (except for a slight weakness for product management in Wallonia, which is probably due to the timing of the evaluation, which was early).

It is also interesting to observe that, while project phasing and product structure scored relatively high (assuming that a systematic approach or a certain structure or methodology has to exist to attain such scores), the practices related to the development methodology axis scored low. These results led us to believe that small settings may develop and use document templates that are traceable to project phases, but without making these practices official. They have the development methodology, but nothing in the organization confirms or institutionalizes it.

\section{Concluding remarks}

This section draws some observations from our experience in by highlighting strengths and weaknesses revealed by the Micro-Evaluation approach.

Recent evaluations in Quebec and France do, in fact, confirm earlier observations in Wallonia. The main one being that Micro-Evaluation is a very attractive tool for our VSE targets. It offers a good cost-effective alternative for small development teams with a low maturity level. Specifically, we can point to several positive features:

- A simplified, low-cost evaluation approach: the obvious merit of a simplified approach is its low cost, which makes it affordable for small organizations with few resources enabling them to initiate concrete and significant process improvement without spending a disproportionate amount in resources. Feedback from assessed organizations, provide evidence about a sound initiation of improvement process. Subsequent evaluation rounds and the number of organizations raised to OWPL evaluation stage and/or to CMM stage, though not observed in a sufficiently large sample and, corroborate that improvement initiations.

In practice, this appears to be the only way to counter the natural tendency, which is to give absolute priority to development tasks and to indefinitely postpone process improvement or quality tasks in general.

- Accurate insight into assessed organizations: Micro-Evaluation is shown to be a very attractive tool to start improvement activities, giving a sufficiently clear view to allow the organization either to begin light improvement action or to go further, into a deeper evaluation. Because the organizations concerned are small, such a simple analysis is sufficient.

- A gradual approach based on continual assessmentimprovement cycles: the fact that the global underlying approach is gradual allows different kinds of tailoring to be performed. For example, evaluation can be tuned to match the available resources, so that even very small structures can use the tool and organize their SPI action plan around it, while larger structures can start their SPI cycle with it to identify weak processes and then go on to an initial OWPL evaluation.

- A context-sensitive approach: an improvement action plan can be set up with accurate insight into the way an organization runs.

- A simplified vocabulary: the simplified vocabulary used makes the tool comprehensible for staff people who are not licensed software engineers or quality specialists. The improvement process concerns management people as well as technicians at different levels. As the number of staff members actually involved in software process improvement increases, the improvement is more likely to be effective if the staff are already sensitized and actively participate in the improvement process.

However, this experience has also highlighted some weaknesses of the approach.

- In practice, a number of Micro-Evaluations were performed on a single project or team, so that the effectiveness of the implementation for the other teams or projects was not evaluated.

- The tool's reference grids appeared to be too vague, so that it is sometimes difficult to properly rate the answers collected.

- Inheriting from traditional reference models such as the $\mathrm{CMM} \circledast$, the tool ignores development practices which are not "disciplined", such as the Agile methods. 
- As mentioned before, reliability of conclusions obtained on basis of one interview of 45 minutes depends of course on the interviewee's vision. Even though these allow to build up practical hypotheses and to go through first improvement cycle, usage should remain cautious before extensive investment. The next step of our methodology -the OWPL evaluation- that requires more than one person to be interviewed for each process should overcome this limitation.

\section{Future Work}

Some of the Micro-Evaluation weaknesses identified in the previous section have already been taken into account in a new version or are under development, while others are planned for future work.

A new version of the Micro-Evaluation tool has been produced to correct all inaccuracies identified in Micro-Evaluation 1.0. In this new version (no more available in open access) the following improvements have been implemented:

- The evaluation scale has been refined to assign four levels to each practice, which facilitates response traceability with respect to the practices evaluated.

- The questions have been ordered in a more flexible and intuitive way in order to facilitate the interview process from the interviewee's point of view.

- The key axis labels have been updated to prevent misinterpretation of the charts generated.

In parallel, another version of the tool, Micro-AgileEvaluation, is being tested. This version has been developed to address organizations and teams using engineering and project management practices deriving from Agile methods (XP, Scrum, DSDM, etc.). It is structured in two parts. The first is aimed at analyzing the project environment from a risk analysis point of view in order to identify factors that could negatively impact the project. The second is made up of four axes covering engineering and management practices (Customer Relationships, Project Management, Development and Testing).

Adaptations to other contexts will also be considered in the near future; in particular, IT service organizations, the main business of which is to produce software for customers only indirectly, and those which produce Free and Open Source software or off-the-shelf software products.

Finally, we should mention that our Micro-Evaluation approach is being considered by Working Group 24 of ISO/IEC JTC1 SC7 as one of the sources for the elaboration of standards and guidelines for the software life cycle in VSEs [3].

\section{References}

[1] SEI (2002) Capability Maturity Model $^{\circledR}$ Integration (CMMi), Version 1.1, CMMi for Software Engineering (CMMi-SW, V1.1) Continuous Representation, CMU/SEI-2002-TR-028, Software Engineering Institute, Pittsburgh, 2002.

[2] ISO/IEC 15504:2003-06, Information Technology - Software Process Assessment (parts 19), International Organization for Standardization.

[3] Laporte, C.Y., April, A, Renault, A., "Applying ISO/IEC Software Engineering Standards in Small Settings: Historical Perspectives and Initial Achievements", Proceedings of the 6th SPICE Conference on Process Assessment and Improvement, Luxembourg, May 2006 pp 57-62.

[4] Habra, N., Niyitugabira, E., Lamblin, A.C. and Renault, A., "Software Process Improvement for Small Structures: First Results of a Micro-Evaluation Framework," in Proceedings of the European Conference on Software Process Improvement SPI'99, Barcelona, Spain, 1999.

[5] Habra, N., Niyitugabira, E., Lamblin, A.C. and Renault, A., "Software Process Improvement in Small Organizations Using Gradual Evaluation Schema," in Proceedings of the International Conference on Product Focused Software Process Improvement PROFES, Oulu, Finland, 1999.

[6] Habra, N., Renault, A., Alexandre, S., Lopez, M., "OWPL - Micro-Evaluation," in Proceedings of the Workshop on Software Quality - International Conference on Software Engineering ICSE, Orlando, Florida, USA, 2002.

[7] Stambollian, A., Habra N., Laporte C.Y., Desharnais J.M., Renault A., "OWPL: A Light Model \& Methodology for Initiating SPI," in Proceedings of the 6th SPICE Conference on Process Assessment and Improvement, Luxembourg, May 2006. pp 97105.

[8] Renault A., Habra N. \& Alexandre S. "OWPL: A Gradual Approach for Software Process Improvement in SMEs, in Proceedings of the 32nd EUROMICRO Conference on Software Engineering \& Advanced Applications, Dubovnic Cratia, Septembre 2006, pp. 328-335,IEEE publ.

[9] Desharnais J.M., Laporte C.Y., Abouelfattah M.M., Bamba J.C., Renault A \& Habra N., "Initiating Software Process Improvement in SMEs: Experiments with Micro-Evaluation Framework", in Proceedings of the SWDC-REK International Conference on Software Development , May-June 2005 Rekjavick, Iceland. 
[10] Hara F., "Irish Experiences with Software Process Improvement," in Proceedings of the European Software Process Improvement Conference 2001, Limerick, Ireland, October, 2001.

[11] Olofsson S., "Tailoring P-CMM for Small Companies," Technical Report UMINF-00.1, Department of Computing Science, Umeå University, 2000.

[12] Richardson I, "SPI Models: What Characteristics Are Required for Small Software Development Companies?" in Proceedings of the ECSQ 2002, 7th International Conference on Software Quality, Helsinki, Finland, June 9-13, 2002,

[13] Johnson D.L. and Brodman J.G., "Tailoring the CMM for Small Businesses, Small Organizations, and Small Projects," IEEE Software Process Newsletter No. 8, Winter 1997

[14] Brodman, J., Johnson, D., "A Software Process Improvement approach Tailored for Small Organizations and Small Projects" in Proceedings of the 1997 International Conference on Software Engineering, (1997), ACM Press, 661-662.

[15] Horvat, R.V., I. Rozman and J. Gyorkos, "Managing the Complexity of SPI in Small Companies". Software Process: Improvement and Practice, 2000. 5(1): p. 45-54.

[16] Saastamoinen, I \& Tukiainen, M, "Software Process Improvement in Small and Medium Sized Enterprises in Eastern Finland: A State-of-thePractice Study". Lecture Notes in Computer Science, Springer, (2004), Vol 3281, pp69-78.

[17] Abrahamsson P., "Commitment to Software Process Improvement-Development of Diagnostic Tool to Facilitate Improvement", Software Quality Journal, 8(1), pp. 63-76, 1999.

[18] Kuvaja P., Palo J. and Bicego A., "TAPISTRY-A Software Process Improvement Approach Tailored for Small Enterprises", Software Quality Journal, 8(2), pp. 149-156, 1999.

[19] Mc Caffery F., Taylor P.S., Coleman G., "Adept: A Unified Assessment Method for Small Software Companies," IEEE Software, vol. 24, no. 1, pp. 24-31, Jan/Feb, 2007.

[20] Richardson I, Gresse von Wangenheim Ch., "Guest Editors' Introduction: Why are Small Software Organizations Different?," IEEE Software, vol. 24, no. 1, pp. 18-22, Jan/Feb, 2007.

[21] Börstler J., Johansson O., Laryd A., Orci T., Segerberg H. and Ågren O., "Quality Management for
Small Enterprises", Technical Report UMINF 02.20, Umeå University, Dec 2002.

[22] (CITA) Cellule Interfacultaire de Technology Assessment, "Utilisation des Systèmes d'Information Inter-Organisationnels par les PME Belges”. Technical Report of the CITA-Computer Sciences Dept., University of Namur, Belgium, November 1997 (in French). 